\title{
PULMONARY METABOLISM OF ENDOTHELIN 1 DURING ON-PUMP AND BEATING HEART CORONARY ARTERY BYPASS OPERATIONS
}

Patrick Mathieu, MD

Jocelyn Dupuis, MD, $\mathrm{PhD}^{\mathrm{b}}$

Michel Carrier, $\mathrm{MD}^{\mathrm{a}}$

Peter Cernacek, $\mathrm{MD}^{\mathrm{b}}$

Michel Pellerin, MD

Louis P. Perrault, MD, PhD

Raymond Cartier, $\mathrm{MD}^{\mathrm{a}}$

Jean Taillefer, $\mathrm{MD}^{\mathrm{c}}$

L. Conrad Pelletier, MD
Background: Coronary artery bypass operations are associated with increased circulating levels of the powerful vasoconstrictor endothelin 1 . The pulmonary circulation is an important site for both production and clearance of endothelin 1. Lung endothelial injury resulting from cardiopulmonary bypass could modify pulmonary endothelin 1 metabolism through an increase in production, a reduction in removal, or a combination of both.

Methods: Pulmonary endothelin 1 kinetics were quantified by using the indicator-dilution technique in patients undergoing coronary artery bypass grafting with $(\mathrm{n}=11)$ or without cardiopulmonary bypass (ie, beating heart; $n=10)$. Mixed venous endothelin 1 levels were also measured in samples from the pulmonary artery, and systemic levels were obtained from the radial artery.

Results: Pulmonary artery endothelin 1 levels were similar before and after cardiopulmonary bypass, with means of $1.59 \pm 0.37 \mathrm{pg} / \mathrm{mL}$ and $1.33 \pm 0.15$ $\mathrm{pg} / \mathrm{mL}(P=.45)$, respectively. Systemic endothelin 1 levels, however, increased after bypass from $1.64 \pm 0.22 \mathrm{pg} / \mathrm{mL}$ to $2.07 \pm 0.16 \mathrm{pg} / \mathrm{mL}$ $(P=.01)$. In the beating heart group, endothelin 1 levels before and after the operation were similar in the pulmonary artery $(1.25 \pm 0.27 \mathrm{pg} / \mathrm{mL}$ and 1.45 $\pm 0.31 \mathrm{pg} / \mathrm{mL}$, respectively; $P=.38)$, as well as in the radial artery $(1.70 \pm$ $0.26 \mathrm{pg} / \mathrm{mL}$ and $1.73 \pm 0.35 \mathrm{pg} / \mathrm{mL}$, respectively; $P=.92)$. The capacity to clear endothelin 1 from the pulmonary circulation, as computed from the permeability-surface area product for endothelin 1, was not affected by cardiopulmonary bypass before and after the operation $(25.19 \pm 2.67 \mathrm{~mL} / \mathrm{s}$ and $23.12 \pm 4.39 \mathrm{~mL} / \mathrm{s}$, respectively; $P=.49)$. It was similar and also unaffected in the beating heart group.

Conclusion: Coronary artery bypass grafting with cardiopulmonary bypass is associated with an increase in systemic endothelin 1 levels. The mechanism involved is not related to a decreased pulmonary clearance of endothelin 1 from the systemic circulation but rather to an increased endothelin 1 release by the lungs. (J Thorac Cardiovasc Surg 2001;121:1137-42)
E ndothelin 1 (ET-1) is an endothelium-derived pepE tide with strong vasoconstrictive and proliferative actions. Increased circulating ET-1 levels have been

From the Departments of Surgery, ${ }^{\mathrm{a}}$ Medicine, ${ }^{\mathrm{b}}$ and Anesthesia, ${ }^{\mathrm{c}}$ Montreal Heart Institute, Montreal, Quebec, Canada.

Supported by the Medical Research Council of Canada, the Quebec Heart and Stroke Foundation, the Fonds de la Recherche en Santé du Québec, and the Fonds de Recherche de l'Institut de Cardiologie de Montréal.

Copyright (C) 2001 by The American Association for Thoracic Surgery

0022-5223/2001 $\$ 35.00+0 \quad \mathbf{1 2 / 1 / 1 1 3 0 2 0}$

doi: $10.1067 / \mathrm{mtc} .2001 .113020$ described in numerous cardiovascular disorders, such as myocardial infarction, ${ }^{1}$ systemic hypertension, ${ }^{2}$ coronary artery spasm, ${ }^{3}$ heart failure, ${ }^{4}$ and pulmonary hypertension. ${ }^{5}$ The human lung is an important site of metabolism for various circulating vasoactive amines and peptides, including ET-1. Reduced clearance or increased production by the pulmonary circulation could contribute to increased circulating ET-1 levels in different cardiovascular diseases. ${ }^{6}$

The plasma concentration of ET-1 increases progressively during cardiopulmonary bypass (CPB). ${ }^{7}$ It is suggested that ET-1 could act as a mediator of perioperative vasospasm. ${ }^{8}$ In an experimental model, postbypass 
pulmonary hypertension was related to ET-1 production during CPB. ${ }^{9}$ The mechanisms responsible for the increase in systemic ET-1 levels during CPB, however, remain largely unresolved. Ischemia-reperfusion with subsequent endothelial injury could affect pulmonary ET-1 metabolism during CPB. A decreased clearance through the endothelial $\mathrm{ET}_{\mathrm{B}}$ receptor or an increased production and release of ET-1 by the pulmonary circulation could be involved. To test this hypothesis, we quantified pulmonary tracer ET-1 kinetics by using a dual-label indicator-dilution technique. To account for possible net clearance or production, we obtained simultaneous measurements of immunoreactive ET-1 levels across the pulmonary circulation. Studies were performed in patients undergoing elective coronary artery bypass grafting $(\mathrm{CABG})$ with or without $\mathrm{CPB}$.

\section{Methods}

The study protocol and consent form were approved by the research and ethics committee of the Montreal Heart Institute. Twenty-one subjects were recruited among patients undergoing elective $\mathrm{CABG}$ procedures. Exclusion criteria were as follows: history of heart failure with ejection fraction of less than $40 \%$; pulmonary hypertension (systolic value $>40 \mathrm{~mm}$ $\mathrm{Hg}$ ); chronic obstructive pulmonary disease; past pulmonary operation; and renal failure with a creatinine level of greater than $200 \mathrm{mmol} / \mathrm{L}$.

The CABG procedures were done with $\mathrm{CPB}$ or with the beating heart technique, depending on preference of the surgeon. In 11 patients CPB was performed by using moderate hemodilution, with hematocrit levels maintained between $20 \%$ and $25 \%$ and systemic hypothermia between $32^{\circ} \mathrm{C}$ and $34^{\circ} \mathrm{C}$. Antegrade blood cardioplegia was used for every patient undergoing CABG with $\mathrm{CPB}$. In 10 patients the CABG operations were done by using the beating heart technique with a myocardial wall stabilizer.

The study protocol was carried out before and immediately after the operation in all the recruited patients. A pulmonary artery catheter (Swan-Ganz catheter; Baxter Healthcare Corp, Edwards Division, Santa Ana, Calif) and a radial artery catheter were inserted before the operation. Radial and pulmonary artery blood samples were simultaneously obtained in ethylenediamine tetraacetic acid tubes for determination of plasma immunoreactive ET-1 levels by using a competitive binding immunoassay, as previously described in detail. ${ }^{10} \mathrm{~A} 5$-cm extension with a 3-way stopcock was added to the pulmonary artery catheter, and a $2-\mathrm{mL}$ bolus mixture for the indicator-dilution study was introduced into the catheter (the bolus was completely contained within the injection system). The radial artery catheter was connected to a Masterflex roller pump (Cole-Parmer Instrument Company, Vernon Hills, Ill) that was connected in turn to a circular fraction collector. The experiment was carried out by rapidly flushing the bolus with $10 \mathrm{~mL}$ of the patient's blood while simultaneously collecting radial artery blood in 60 consecutive tubes ( 1.2 seconds per tube) at a rate of $50 \mathrm{~mL} / \mathrm{min}$. A 2-
$\mathrm{mL}$ sample of blood was then taken from the injection lines to determine the amount of residual activity retained in the injection system.

The injection mixture was prepared under sterile conditions. Human albumin (25\%) was added to $3 \mathrm{~mL}$ of Evans blue dye $(5 \mathrm{mg} / \mathrm{mL})$ to obtain a final bolus concentration of $4 \%$ albumin. The blue dye tightly binds to albumin and serves as a vascular reference from which tracer ET-1 kinetics are computed. Iodine 125-labeled ET-1 (10 $\mu \mathrm{Ci})$ (Dupont, Wilmington, Del; NEN Life Science Products, Inc, Boston, Mass; $2200 \mathrm{Ci} / \mathrm{mmol}$ ) was then added to the mixture. The final volume was approximately $3.5 \mathrm{~mL}$ per experiment; 2 $\mathrm{mL}$ was taken to constitute the bolus administered to the patient, and the remaining $1.5 \mathrm{~mL}$ was kept for the preparation of dilution curve standards. All collected tubes, 1:10 and 1:100 diluted standards, and injection line samples were treated identically. Blood $(200 \mu \mathrm{L})$ was pipetted from each tube and assayed in a gamma counter to determine iodine 125 activity. The remaining samples were centrifuged at 3000 rpm for 10 minutes, and $100 \mu \mathrm{L}$ of plasma was drawn and added to $1.0 \mathrm{~mL}$ of $0.9 \% \mathrm{NaCl}$ in spectrophotometer cuvettes for measurement of Evans blue dye absorbance $(620 \mathrm{~nm}$ minus $740 \mathrm{~nm}$ ). The exact quantity of tracers injected was determined by subtracting the activity retained in the injection system from the amount contained in the 2-mL bolus. For each sample, the fractional recoveries of tracer ET-1 and albumin were determined. A plot of the fractional recoveries per milliliter of blood as a function of time was then constructed to obtain the indicator-dilution curve for each tracer. The albumin is used as a plasmatic vascular reference tracer. Cardiac output can then be computed as follows:

$$
\text { cardiac output }=q_{0} \int_{0}^{\infty} a l b(t) d t
$$

where $\mathrm{q}_{\mathrm{o}}$ is the total amount of Evans blue dye-bound albumin injected, and the denominator represents the area under the fractional recovery versus time curve for the same tracer. The recirculating tracer is mathematically removed by means of linear extrapolation of the exponential downslope on a semilogarithmic plot. Mean tracer ET-1 extraction is calculated with the following equation:

$$
\text { extraction }=1-\int_{0}^{\infty} E T(t) d t / \int_{0}^{\infty} a l b(t) d t
$$

where the right term represents the difference in the areas of the fractional recovery versus time curves for tracer albumin and ET. Mean tracer ET-1 extraction will vary not only with the activity of the removal process $\left(\mathrm{ET}_{\mathrm{B}}\right.$ receptor density and activity) but also with pulmonary blood flow. The metabolic capacity of the lungs to clear ET-1 from the circulation was thus evaluated by computation of the permeability-surface area (PS) product for ET-1 removal. The PS product, which is equivalent to a plasmatic clearance, is used to describe the unidirectional uptake of permeating tracers by using the indicator-dilution technique. ${ }^{11,12}$ We have previously validated the use of the PS product to evaluate pulmonary removal of tracer ET-1 and demonstrated its stability over a wide range of pulmonary blood flow, despite the expected 
Table I. Hemodynamic data in patients operated on with CPB and without CPB (beating heart group)

\begin{tabular}{|c|c|c|c|c|}
\hline & \multicolumn{2}{|c|}{$C P B$} & \multicolumn{2}{|c|}{ Beating heart } \\
\hline & Preoperative & Postoperative & Preoperative & Postoperative \\
\hline HR (beats/min) & $65 \pm 3$ & $75 \pm 3^{*}$ & $63 \pm 4$ & $69 \pm 3$ \\
\hline $\mathrm{BP}(\mathrm{mm} \mathrm{Hg})$ & $84 \pm 2$ & $80 \pm 3$ & $79 \pm 2$ & $76 \pm 2$ \\
\hline CVP (mm Hg) & $10 \pm 1$ & $12 \pm 1$ & $10 \pm 1$ & $10 \pm 2$ \\
\hline MPA (mm Hg) & $21 \pm 2$ & $21 \pm 2$ & $17 \pm 2$ & $20 \pm 3$ \\
\hline $\mathrm{CI}\left(\mathrm{L} \cdot \mathrm{min}^{-1} \cdot \mathrm{m}^{-2}\right)$ & $2.4 \pm 0.2$ & $3.3 \pm 0.1 \dagger$ & $2.6 \pm 0.3$ & $2.5 \pm 0.2$ \\
\hline
\end{tabular}

$H R$, Heart rate; $B P$, blood pressure; $C V P$, central venous pressure; $M P A$, mean pulmonary artery pressure; $C I$, cardiac index.

$* P=.05$, preoperative versus postoperative value in the CPB group.

$\dagger P=.0003$, preoperative versus postoperative value in the CPB group.

variations in mean tracer ET extraction. ${ }^{4}$ The PS product for ET-1 removal by the pulmonary circulation was computed as follows:

$$
\mathrm{PS}=-\mathrm{Fp} \times \ln (1-\mathrm{Ext})
$$

where Fp is the pulmonary plasma flow in milliliters per second and Ext is mean tracer ET-1 extraction.

All values are reported as means \pm SEM. Companion radial and pulmonary artery ET-1 levels were compared by using 2 -tailed paired $t$ tests. Unpaired 2-tailed $t$ tests were used to compare data between the 2 groups. Hemodynamic data (before and after the operation) were compared by using paired $t$ tests. Linear regression was used to detect correlation between the cardiac index and mean tracer ET-1 extraction.

\section{Results}

The mean age in the CPB group ( $61.7 \pm 2$ years) was not different from that of the beating heart group (64.4 \pm 3 years; $P=.63$ ). The average ejection fraction was also similar at $0.61 \pm 0.04$ and $0.58 \pm 0.05$ for the $\mathrm{CPB}$ and beating heart groups, respectively $(P=.89)$. The mean numbers of bypass grafts were $2.9 \pm 0.3$ and 2.5 \pm 0.2 , respectively, for the $\mathrm{CPB}$ and beating heart groups $(P=.18)$. In the $\mathrm{CPB}$ group the average $\mathrm{CPB}$ time was $65.0 \pm 5.9$ minutes, and the crossclamp time was $44.6 \pm 5.7$ minutes. Before the operation, both groups had similar heart rates, mean arterial blood pressures, central venous pressures, and pulmonary artery pressures (Table I). After the operation, heart rate increased in the CPB group from $65 \pm 3$ beats/min to $75 \pm 3$ beats $/ \min (P=.05)$, as did the cardiac index from $2.4 \pm 0.2$ to $3.3 \pm 0.1 \mathrm{~L} \cdot \mathrm{min}^{-1} \cdot \mathrm{m}^{-2}(P=.0003)$. In the beating heart group hemodynamic parameters were not affected by the procedure.

In the CPB group pulmonary artery ET-1 levels were not modified, with means of $1.59 \pm 0.37 \mathrm{pg} / \mathrm{mL}$ before and $1.33 \pm 0.15 \mathrm{pg} / \mathrm{mL}$ after the procedure $(P=.45$, Fig 1). Systemic levels measured in the radial artery, however, increased from $1.64 \pm 0.22 \mathrm{pg} / \mathrm{mL}$ to $2.07 \pm 0.16$ $\mathrm{pg} / \mathrm{mL}(P=.01)$. In the beating heart group mean levels of ET-1 were not affected when compared with respective preoperative value (Fig 2). Mean pulmonary artery levels of ET-1 $(1.25 \pm 0.27 \mathrm{pg} / \mathrm{mL}$ and 1.45 $\mathrm{pg} / \mathrm{mL}$, respectively, before and after the procedure; $P$ $=.38$ ) and systemic levels measured in the radial artery $(1.70 \pm 0.26 \mathrm{pg} / \mathrm{mL}$ and $1.73 \pm 0.35 \mathrm{pg} / \mathrm{mL}$, respectively, before and after the operation; $P=.92$ ) were not different. Before the operation, there was no ET-1 gradient across the lungs in the CPB group, whereas there was a significant $56 \%$ positive gradient after the operation $(P=.0004)$. In the beating heart group there was a significant $36 \%$ positive ET- 1 gradient before the operation $(P=.01)$, which was reduced to $19 \%$ and no longer significant after the operation $(P=.01)$.

Mean pulmonary iodine 125-labeled ET-1 extraction decreased after the operation in the CPB group from $40.9 \% \pm 4.0 \%$ to $24.4 \% \pm 4.7 \%(P=.0001)$ and was not affected in the beating heart group $(43.0 \% \pm 6.0 \%$ and $36.6 \% \pm 6.1 \%$, respectively, before and after the operation; $P=.2$ ). The reduction in tracer ET-1 extraction in the CPB group correlated inversely with the observed increase in cardiac index after the operation $(r$ $=-0.43, P<.005)$. The pulmonary metabolic capacity to clear ET-1 from the circulation, as computed from the PS product, remained stable before and after the operation in both the CPB group $(25.2 \pm 2.7 \mathrm{~mL} / \mathrm{s}$ and $23.1 \pm 4.4 \mathrm{~mL} / \mathrm{s}$, respectively; $P=.49$; Fig 3 ) and the beating heart group $(29.4 \pm 5.4 \mathrm{~mL} / \mathrm{s}$ and $27.7 \pm 5.0$ $\mathrm{mL} / \mathrm{s}$, respectively; $P=.63$; not shown).

\section{Discussion}

$\mathrm{CPB}$ is associated with a systemic inflammatory response and the release of numerous vasoactive substances. ${ }^{13}$ Increased systemic levels of ET-1 during CPB have previously been documented ${ }^{14}$ and are confirmed in the present study. There was a significant positive arteriovenous ET-1 gradient in patients undergoing operations with CPB. It has been suggested that the arteriovenous gradient is related to a decreased pulmonary clearance of ET- $1 .{ }^{14}$ However, a simple analysis of the transpulmonary gradient, analogous to a 


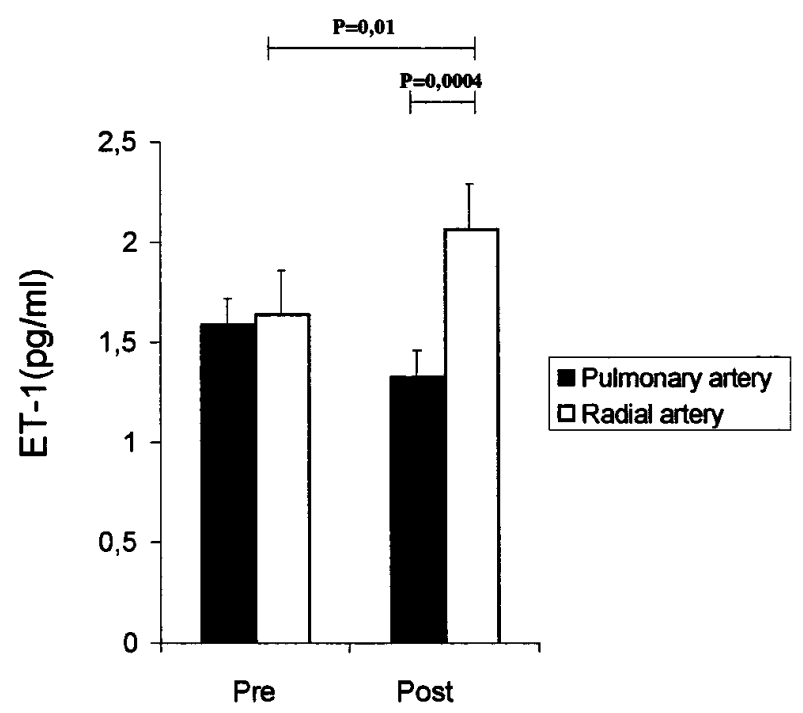

Fig 1. Preoperative and postoperative plasma ET-1 levels measured in the pulmonary and radial artery in the CPB group.

black box analysis, does not provide all the information about the pulmonary metabolism of ET-1. Use of the indicator-dilution technique in combination with measurements of arteriovenous ET-1 levels allows for discrimination between removal and production within the black box. Emphasizing this concept, we have shown that the normal human pulmonary circulation demonstrates minimal or no arteriovenous ET-1 gradient, despite close to $50 \%$ tracer ET-1 extraction. The normal lungs therefore produce and release ET-1 into the circulation in an amount equal to the quantity extracted. ${ }^{6}$ Animal studies have established the lungs as one of the major sites for ET-1 removal mediated through the endothelial $\mathrm{ET}_{\mathrm{B}}$ receptor, as well as for ET-1 production. ${ }^{15}$ Increased ET-1 transpulmonary gradients could therefore be related to a decreased removal of ET-1, an increase in production, or a combination of both. The indicator-dilution technique combined with the measurement of ET-1 has been used in this study to precisely quantify pulmonary ET-1 metabolism during cardiac operations.

According to the model we used, ${ }^{11}$ mean pulmonary tracer ET-1 extraction will correlate directly with the activity of the removal process (endothelial ET $_{B}$ density and activity) and the metabolically active pulmonary vascular surface area but indirectly with pulmonary plasma flow. We found that mean tracer ET-1 extraction was significantly reduced after the surgical procedure in the CPB group but that this correlated inversely with

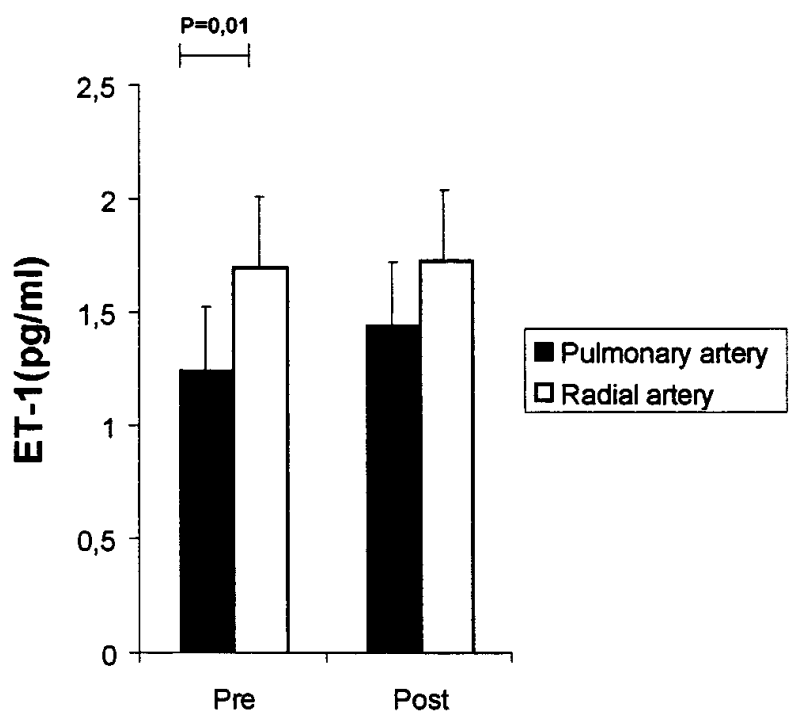

Fig 2. Preoperative and postoperative plasma ET-1 levels measured in the pulmonary and radial artery in the beating heart group.

the observed increase in cardiac index for the same patients. Using isolated rat lungs, we have validated this model and demonstrated that mean tracer ET-1 extraction varies inversely with increases in plasma flow: the computed PS product, which accounts for this variability, remains remarkably constant over a wide range of blood flows, however. ${ }^{4}$ In fact, only in the transition from very low to higher flow rates did we find a tendency for an increase in the PS product, probably because of an increase in metabolically active surface caused by lung capillary recruitment. In the present study we found that the metabolic capacity of the lungs to remove ET-1 from the circulation, as computed from the PS product, was similar in the CBP and beating heart groups and did not vary after the surgical procedure. This therefore suggests that the increased transpulmonary ET-1 gradient observed in the CPB group is not related to a decreased clearance but rather to an increase in pulmonary ET-1 production and release into circulation.

The hemodynamic effects of ET- 1 are mediated by 2 receptor subtypes. The $\mathrm{ET}_{\mathrm{A}}$ receptors are located on the vascular smooth muscle cells and mediate vasoconstriction, whereas the $\mathrm{ET}_{\mathrm{B}}$ receptors are located on endothelial cells, where they are responsible for vasodilation through the production of nitric oxide and prostacyclin. ${ }^{16}$ Endothelial $\mathrm{ET}_{\mathrm{B}}$ receptors are also responsible for pulmonary clearance of ET-1, ${ }^{15}$ with their blockade causing an increase in circulating ET-1 
levels. The $\mathrm{ET}_{\mathrm{B}}$ receptors are also present on the vascular smooth muscle, where they also mediate vasoconstriction on stimulation. Rats with heart failure caused by coronary artery ligation demonstrate reduced pulmonary ET-1 clearance that correlates well with the increase in circulating ET-1 levels. ${ }^{17}$ The reported reduction in pulmonary $\mathrm{ET}_{\mathrm{B}}$ receptor density, ${ }^{18}$ as well as $\mathrm{ET}_{\mathrm{B}}$ mRNA expression and protein level, ${ }^{19}$ in this model support the hypothesis that a reduced pulmonary ET-1 clearance is caused by endothelial dysfunction, with reduced activity or density of the $\mathrm{ET}_{\mathrm{B}}$ receptor. The present study suggests that CPB does not affect endothelial $\mathrm{ET}_{\mathrm{B}}$ integrity and function because the pulmonary removal of ET-1 was not affected by the procedure. The observed increase in systemic ET-1 levels after CPB operations, but not after beating heart operations, must therefore be caused by an increased pulmonary production and release of the peptide.

Before the operation, there was no pulmonary ET-1 gradient in the CPB group, although there was a positive $36 \%$ gradient in the beating heart group. This suggests that the beating heart group had a net pulmonary ET-1 release present at baseline, whereas the CPB group, with no gradient, had a release that matched removal. After the operation, the beating heart group demonstrated no variation in systemic ET-1 levels and demonstrated a positive, although no longer significant, $19 \%$ transpulmonary ET-1 gradient. Consequently, even if baseline ET-1 equilibriums across the pulmonary circulation were different between the 2 groups, possibly because of interindividual variability, our data demonstrate that the balance was strongly shifted to a net pulmonary release of ET-1 in the CPB group (from no gradient to $56 \%$ positive gradient), whereas in the beating heart group there was a tendency for a net reduction in ET-1 release by the lungs (from $36 \%$ to $19 \%$ positive gradient).

The exact mechanisms behind the increased ET-1 concentration after CPB are unknown. However, surgical stress $^{20}$ and hypothermia ${ }^{21}$ are known to increase ET-1 levels. We failed to find any significant increase in both mixed venous and arterial ET-1 levels in the beating heart groups. This suggests that the surgical stress itself was not the most important variable affecting ET-1 production and that procedures associated with the CPB itself are more important in the activation of the ET system during cardiac operations. Although we have found elevated concentrations of ET-1 after CPB, these circulating levels are probably too low to exert any systemic vasoactive effect. It is widely accepted that ET-1 is a mostly paracrine mediator so that circulating ET-1 generally represents a local spillover indicative of increased

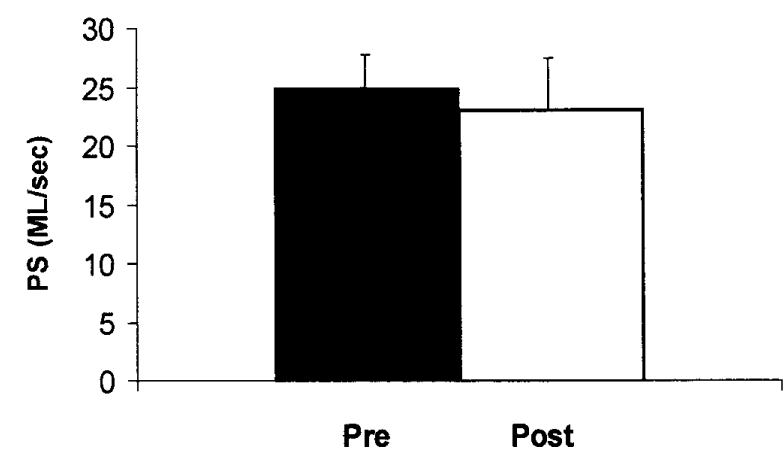

Fig 3. PS product in the CPB group: preoperative and postoperative value $(P=.49)$.

tissue ET-1 production, where concentrations may reach pathophysiologic significance. This concept is supported by a pathologic animal model in which post-CPB pulmonary hypertension was reduced by acute ET receptor blockade. ${ }^{22}$ In our patients the pulmonary artery pressure did not significantly change before and after the procedure in either group (CPB and beating heart group). However, this was not surprising because those patients had normal preoperative pulmonary artery pressure. In a lamb model the pre-existing pulmonary circulation status influences the pulmonary vascular resistance after CPB. ${ }^{23}$ Consequently, in patients with pre-existing pulmonary hypertension, it is possible that the local increase in pulmonary production of ET-1 could be greater and lead to significant deterioration of pulmonary hemodynamics, although this remains speculative at this point.

CABG with the beating heart technique avoids the important inflammatory reaction observed with CPB. CPB exposes blood to artificial membranes and triggers an important inflammatory reaction. ${ }^{7}$ ET-1, through its proinflammatory effects, could contribute to this process. In vitro ET-1 stimulates monocytes and macrophages to release tumor necrosis factor $\alpha$, interleukin $1 \beta$, and interleukin $8 .^{24}$ The ET- 1 proinflammatory effects could affect the local and systemic inflammatory reaction. The exact roles of ET-1 as a proinflammatory and vasoactive molecule during CPB remain unknown.

This was a nonrandomized study in which the choice of CABG with or without CPB was at the discretion of the attending surgeon. Considering the small number of patients in each group, a selection bias may have affected the results. The presence of a mild positive ET-1 gradient before the operation in the beating heart group with no such gradient in the CPB group may be related to these limitations. 
Within groups, paired comparisons, however, demonstrated a net increase in arterial ET-1 only in the CPB group, supporting our conclusion of an increased pulmonary ET-1 production only in this group.

\section{Conclusion}

We have shown that $\mathrm{CABG}$ with $\mathrm{CPB}$ causes an increase in ET-1 levels across the pulmonary circulation. This is not related to a reduced pulmonary removal of this peptide but rather to an increase in pulmonary production and release into the circulation. Operations with the beating heart technique did not modify pulmonary ET-1 kinetics. Further studies are needed to precisely identify the potential pathophysiologic role of ET-1 during CPB.

We thank Nathalie Ruel for her expert technical assistance.

Received for publication March 29, 2000; revisions requested Sept 8, 2000; revisions received Oct 11, 2000; accepted for publication Nov 16, 2000.

Address for reprints: Jocelyn Dupuis, MD, PhD, Research Center, Montreal Heart Institute, 5000 Belanger St E, Montreal, Quebec H1T 1C8, Canada (E-mail: dupuisj@icm.umontreal.ca).

\section{REFERENCES}

1. Miyauchi T, Yanagisawa M, Tomizawa T, Sugishita Y, Suzuki N, Fujino M, et al. Increased plasma concentrations of endothelin-1 and big endothelin-1 in acute myocardial infarction. Lancet 1989;2:53-4.

2. Saito Y, Nakao K, Mukoyama M, Imura H. Increased plasma endothelin level in patients with essential hypertension. N Engl J Med 1990;322:205.

3. Toyo-oka T, Aizawa T, Suzuki N, Hirata Y, Miyauchi T, Shin WS, et al. Increased plasma levels of endothelin-1 and coronary spasm induction in patients with vasospastic angina pectoris. Circulation 1991;83:476-83.

4. Dupuis J, Moe GW, Cernacek P. Reduced pulmonary metabolism of endothelin-1 in canine tachycardia-induced heart failure. Cardiovasc Res 1998;39:609-16.

5. Dupuis J, Cernacek P, Tardif JC, Stewart DJ, Gosselin G, Dyrda I, et al. Reduced pulmonary clearance of endothelin-1 in pulmonary hypertension. Am Heart J 1998;135:614-20.

6. Dupuis J, Stewart DJ, Cernacek P, Gosselin G. Human pulmonary circulation is an important site for both clearance and production of endothelin-1. Circulation 1996;94:1578-84.

7. Downing SW, Edmunds LH. Release of vasoactive substances during cardiopulmonary bypass. Ann Thorac Surg 1992;54:1236-43.

8. Haak T, Matheis G, Kohleisen M, Ngo H, Beyersdorf F, Usadel $\mathrm{KH}$. Endothelin during cardiovascular surgery: the effect of diltiazem and nitroglycerin. J Cardiovasc Pharmacol 1995;26(Suppl 3):S494-6.
9. Kirshbom PM, Tsui SL, DiBernardo LR, Meliones JN, Schwinn DA, Ungerleider RM, et al. Blockade of endothelin-converting enzyme reduces pulmonary hypertension after cardiopulmonary bypass and circulatory arrest. Surgery 1995;118:440-5.

10. Dupuis J, Goresky CA, Stewart DJ. Pulmonary removal and production of endothelin in the anesthetized dog. J Appl Physiol 1994;76:694-700.

11. Crone C. The permeability of capillaries in various organs as determined by use of the indicator diffusion method. Acta Physiol Scand 1963;58:292-305.

12. Bassinghtwaighte JB, Chinard FP, Crone C, Goresky CA, Lassen NA, Reneman RS, et al. Terminology of mass transport and exchange. Am J Physiol 1986;250:H539-45.

13. Downing SW, Edmunds LH. Release of vasoactive substances during cardiopulmonary bypass. Ann Thorac Surg 1992;54:123643.

14. Matheis G, Haak T, Beyersdorf F, Baretti R, Polywka C, Winkelmann BR. Circulating endothelin in patients undergoing coronary artery bypass grafting. Eur J Cardiothorac Surg 1995;9:269-74.

15. Dupuis J, Goresky CA, Fournier A. Pulmonary clearance of circulating endothelin-1 in dogs in vivo: exclusive role of ETB receptors. J Appl Physiol 1996;81:1510-5.

16. Luscher TF, Yang Z, Tschudi M, von Segesser L, Stulz P, Boulanger $\mathrm{C}$, et al. Interaction between endothelin-1 and endothelium-derived relaxing factor in human arteries and veins. Circ Res 1990;66:1088-94.

17. Dupuis J, Rouleau JL, Cernacek P. Reduced pulmonary clearance of endothelin- 1 contributes to the increase of circulating levels in heart failure secondary to myocardial infarction. Circulation 1998;98:1684-7.

18. Cernacek P, Stewart DJ, Rouleau JL. Tissue profile of endothelin1 in heart failure [abstract]. Clin Invest Med 1995;18:B12.

19. Kobayashi T, Miyauchi T, Sakai S, Maeda S, Yamagushi I, Goto $\mathrm{K}$, et al. Down-regulation of ETB receptor, but not ETA receptor, in congestive lung secondary to heart failure. Life Sci 1998;62:185-93.

20. Tuominen HP, Svartling NE, Tikkanen IT, Saijonmaa O, AskoSeljavaara S. Perioperative plasma endothelin-1 concentrations and vasoconstriction during prolonged plastic surgical procedures. Br J Anaesth 1995;74:661-6.

21. Fyhrquist F, Saijonmaa O, Metsarinne K, Tikkanen T. Raised plasma endothelin-1 concentrations following cold pressor test. Biochem Biophys Res Commun 1990;169:217-21.

22. Petrossian E, Parry AJ, Reddy VM, Akkersdijk GP, McMullan MD, ThompsonL, et al. Endothelin receptor blockade prevents the rise in pulmonary vascular resistance after cardiopulmonary bypass in lambs with increased pulmonary blood flow. J Thorac Cardiovasc Surg 1999;117:314-3.

23. Reddy VM, Hendricks Munoz K, Rajasinghe HA, Petrossian E, Hanley FL, Fineman JR. Post-cardiopulmonary bypass pulmonary hypertension in lambs with increased pulmonary blood flow: a role for endothelin-1. Circulation 1997;95: 1054-61.

24. Helset E, Ytrehus K, Tveita T, Kjaeve J, Jorgensen L. Endothelin1 causes accumulation of leucocytes in the pulmonary circulation. Circ Shock 1994;44:201-9. 